\title{
REPRESENTACIONES DE PERPETRADORES DE CRÍMENES NAZI EN EXPOSICIONES MUSEOGRÁFICAS EN ALEMANIA
}

\author{
REPRESENTATIONS OF PERPETRATORS OF NAZI CRIMES \\ IN MUSEOGRAPHIC EXHIBITIONS IN GERMANY
}

\section{JO SIEMON ${ }^{\star}$}

Resumen: A través de la revisión de las exposiciones Wehrmachtsausstellung I y II, y del concepto expositivo en el sitio de memoria Wewelsburg (lugar representativo de las SS), ambos en Alemania, este artículo reflexiona acerca de los criterios museográficos de las exposiciones, su contexto social contemporáneo, y plantea preguntas éticas acerca de los objetivos, medios y desafíos de exposiciones que buscan generar un impacto en el imaginario público, para así aportar al debate sobre la representación de los perpetradores de crímenes de lesa humanidad o violaciones a los derechos humanos y proponer conclusiones para el debate chileno.

Palabras Clave: Perpetradores de crímenes del nacionalsocialismo, violadores de los derechos humanos, criterios museográficos, Wehrmachtsausstellung, Wewelsburg.

Aвstract: Through the review of the exhibitions Wehrmachtsausstellung I and II, and the exhibition concept on the memory site Wewelsburg (representative place of the SS), both in Germany, this article reflects on the museographic criteria for the exhibitions, their contemporary social context and ethical questions about the objectives, media and challenges of exhibitions that seek to generate an impact on the public imagination, in order to contribute to the debate on the representation of perpetrators of crimes against humanity or human rights violations and to propose conclusions for the Chilean debate.

KEYwORDs: Perpetrators of Nazi crimes, human rights violators, museographic criteria, Wehrmachtsausstellung, Wewelsburg.

Recibido: 2019-02-01. Aceptado: 2020-09-02.

\section{INTRODUCCIÓN}

Cen la exposición "Hijos ha generado la inclusión de Augusto Pinochet en la exposición "Hijos de la libertad" en el Museo Histórico Nacional

\footnotetext{
* Magíster en Historia. Investigadora independiente. Correo electrónico: josiemon@hotmail.de. Orcid: https://orcid.org/0000-0002-6232-8904.
} 
de Chile, da pie para discutir sobre la representación de perpetradores de crímenes de lesa humanidad o violadores de derechos humanos (DD.HH.). En este contexto, este artículo se enfoca en la temática museográfica, donde diversos críticos de la mencionada exposición denunciaron el modo de representación museográfica que ubica a Pinochet en la misma categoría que Salvador Allende, Elena Caffarena y Gabriela Mistral, entre otros (Basaure, 2018).

En Chile, no ha habido exposiciones sobre perpetradores de las violaciones de DD.HH. en Dictadura, por lo que resulta necesario analizar los criterios museográficos para distinguir entre la representación de diferentes actores con connotaciones éticas distintas. Este artículo busca aportar al debate sobre la representación de perpetradores en museos y sitios de memoria, a partir de una revisión de criterios museográficos para la exposición de perpetradores del terror nacionalsocialista en Alemania, considerando las exposiciones Wehrmachtsausstellung I y II (1995 y 2002) que abordan el rol del ejército alemán en los crímenes de la Segunda Guerra Mundial; y el concepto museográfico de la nueva exposición permanente del sitio de memoria Wewelsburg (lugar representativo de la SS) en 2010. Así, la pregunta que guía este trabajo es, ¿cómo los debates académicos o intelectuales se han traducido en conceptos museográficos?

La estructura consta de cinco secciones. Luego de la introducción, la segunda sección aborda el contexto específico de Alemania en relación con la representación e investigación de los perpetradores de los crímenes nazi, además da un breve resumen de la investigación sobre violadores de DD.HH. y su representación en Chile. La tercera sección revisa los aportes de las exposiciones al desarrollo de criterios museográficos para la representación de estos perpetradores en museos y sitios de memoria. Luego, la cuarta sección propone una discusión sobre desafíos éticos que derivan de esta representación en Alemania, y la última sección presenta las conclusiones relacionadas con el caso chileno.

\section{LA IMPORTANCIA DE LOS CONTEXTOS}

Incluir representaciones de los perpetradores de los crímenes nazi en sitios históricos y exposiciones museográficas en Alemania ha resultado muy enriquecedor, a pesar del desafío que ha significado. Especialmente para el trabajo educativo en memoria y DD.HH., este debate ha abierto nuevas posibilidades de reflexión que vinculan el pasado con las nuevas genera- 
ciones. Sin embargo, para la sociedad alemana ha sido un proceso largo de varias décadas, que ha pasado por diferentes etapas desde la negación y la demonización de unos pocos individuos perpetradores hasta la banalidad del mal, según Hannah Arendt (1999), y la investigación de las condiciones de la violencia, a través de la pregunta "¿Cómo personas comunes y corrientes llegan a ser asesinos de masas?” (Welzer, 2005, p. 3). Frank Bajohr (2013, pp. 2-4) resume la investigación sobre perpetradores, haciendo énfasis en cómo diferentes investigadores (Browning, 2011; Greve, 2003; Musial, 1999) han cuestionado las representaciones que descansaban en la demonización de algunos pocos victimarios mostrándolos como monstruosos y omnipotentes. En cambio, estos autores han buscado ampliar el concepto de "perpetrador" y de "organizaciones perpetradoras", yendo más allá de la dualidad de víctimas y victimarios, investigando matices como, por ejemplo, a través de las categorías "colaborador", "administrativo", "delator" y "observador" (Bajohr, 2013).

Este nuevo tipo de enfoques, que buscan complejizar la reflexión acerca de cómo estas personas se volvieron perpetradores de crímenes de lesa humanidad o al menos cómplices del sistema genocida, requieren un enfoque multicausal, que atiende al menos tres aspectos: 1) La organización institucional considera que la división de trabajo entre las instituciones que participaron en el Holocausto permitió que cada uno de los involucrados pudiera desligarse de su responsabilidad, aun sabiendo, por ejemplo, el destino de las deportaciones que organizaban; 2) La situación misma del crimen tiene que ver con la presión social del grupo de pares y superiores, y con el contexto social: la propaganda ideológica y deshumanizante, la marginalización del supuesto enemigo, la pérdida de empatía y la naturalización de la violencia; 3) El Handlungsspielraum individual que tiene cada persona de sus propios actos, o sea, la responsabilidad que emana de la libertad de poder actuar de una u otra manera frente a una situación u orden (Bajohr, 2013; Wildt, 2002).

Estudios de casos como el de Browning (2011) sobre la policía muestran que hubo diferentes motivaciones por parte de los perpetradores de los crímenes nazi para participar en el Holocausto y que inclusive los perpetradores de matanzas masivas tuvieron dicho Handlungsspielraum (Bajohr, 2013; Gryglewski, 2017). Este último aspecto nos lleva a uno de los objetivos principales de la investigación en torno a la representación de perpetradores en Alemania: interpelar al público con la pregunta por la responsabilidad individual por nuestros actos en la historia y en el presente.

Estas reflexiones se generaron en el contexto específico alemán, carac- 
terizado, en primer lugar, porque la mayoría de las personas que vivieron en Alemania en los años de posguerra eran hijos de perpetradores de crímenes nazi, colaboradores y/o observadores, ya que la mayoría de las víctimas no sobrevivió el Holocausto o tuvo que exiliarse. El debate sobre la Wehrmachtsausstellung demuestra que esta composición social condiciona la investigación y el debate sobre los perpetradores del nazismo de una $\mathrm{u}$ otra manera. En segundo lugar, al momento de investigar o exponer los crímenes de lesa humanidad cometidos durante la Segunda Guerra Mundial y el Holocausto, surge el problema de que la gran mayoría de las fuentes históricas fueron generadas por los mismos perpetradores nazi y, por ende, reflejan su visión, sus ideologías y prejuicios. Estos documentos pueden seguir transmitiendo el mensaje original de sus autores, usando, por ejemplo, retórica antisemita o eufemismos para legitimar y esconder los crímenes cometidos ${ }^{1}$. Para analizar estas fuentes y entender la extensión de los crímenes cometidos, hay que reconocer, descifrar y contrastar el lenguaje usado. Además, es imprescindible tener en consideración que las perspectivas de las víctimas no están presentes en los documentos de los nazi. Por lo mismo, es importante contrastar estas fuentes con las voces y perspectivas de las víctimas, ya que únicamente estos testimonios ponen en perspectiva el relato de los perpetradores del nazismo, permitiendo deconstruir sus miradas y demostrar la magnitud del dolor y trauma sufrido.

La investigación sobre los violadores de DD.HH. en Chile está recién comenzando, y las preguntas del campo académico han estado más bien orientadas en torno a las víctimas. Las agrupaciones de familiares y ex presos políticos todavía están activas en la sociedad; igual que los victimarios. Así, la mirada hacia los perpetradores está vinculada a las expectativas de justicia y la reconstrucción de la verdad sobre los detenidos desaparecidos, a la lucha por la recuperación de sitios de memoria, así como a la lucha por la autoridad sobre la interpretación pública del pasado. Sin embargo, en los últimos años han surgido trabajos que abordan nuevos aspectos, revisando la participación de civiles y el empresariado, o los matices entre víctima y victimario (Lazzara, 2018; Rebolledo, 2012). Además, resalta la investigación de Passmore (2017) sobre el rol ambiguo de los conscriptos durante la dictadura y también, el concepto de violador de DD.HH. en la opinión pública (Jara, 2016). Estos trabajos cuestionan la representación pública del

\footnotetext{
${ }^{1}$ Por ejemplo, tras el término 'eutanasia' (la muerte sin sufrimiento) se esconde el asesinato sistemático de personas con discapacidad; 'evacuar' y 'trato especial' son eufemismos para la deportación de millones de personas hacia los guetos y campos de concentración a fin de asesinarlos.
} 
perpetrador de violaciones de los DD.HH. comúnmente limitado a Pinochet, y la limitación binaria entre víctima y victimario, e introducen nuevos matices.

A pesar de estas recientes investigaciones que buscan matizar el concepto de perpetrador en tiempos de dictadura, la representación de este en exposiciones museográficas sigue siendo muy baja. El sitio de memoria Parque por la Paz - Villa Grimaldi hace mención a (organismos) perpetradores de violaciones de los DD.HH. en su relato de audioguía, sus guiones de visitas y en su exposición. En esta última se incluye un dibujo que muestra tres diferentes tipos de perpetradores que operaban en el sitio y un organigrama con nombres y fotos de los integrantes del organismo represor que funcionó allí. A raíz del aumento de interés de las audiencias en este tema, el equipo del sitio discute actualmente profundizar este aspecto en su narrativa (Rebolledo y Sagredo, 2020). Sin embargo, la museografía actual es coherente con el concepto de la búsqueda de verdad y justicia, identificando a los victimarios y sus diferentes roles en el sitio. Dada la naturaleza de los sitios y el Museo de Memoria, para ellos los organismos perpetradores de violaciones de los DD.HH. y sus miembros no son objeto de análisis más allá de la investigación judicial y la contextualización de casos.

Visto lo anterior, es importante tener en cuenta que los contextos específicos de los dos países impiden una transferencia directa de las experiencias alemanas al caso chileno. Más bien, los criterios elaborados en Alemania pueden verse como un punto de partida, considerando que el debate chileno tendrá que generar sus propias respuestas desde y para el contexto chileno.

\section{DEL CONOCIMIENTO ACADÉMICO A LA OPINIÓN PÚBLICA}

La Wehrmachtsausstellung I y II fueron dos exposiciones itinerantes sobre la participación de la Wehrmacht (ejército alemán entre 1935-1945) en los crímenes de lesa humanidad durante la Segunda Guerra Mundial en el este de Europa contra la Unión Soviética; ambas fueron elaboradas por la fundación académica Hamburger Institut für Sozialforschung ${ }^{2}$. Como se demostrará, la primera exposición resalta por la situación social del momento de su presentación y por la falta de criterios concretos para la representación de perpetradores de los crímenes del nacionalsocialismo. A partir

${ }^{2}$ El HIS es un instituto privado e independiente de investigación social. www.his-online.de/ 
de los problemas de la primera exposición, la segunda introduce criterios museográficos-académicos y preguntas inquietantes para involucrar a las audiencias y a las nuevas generaciones.

La presente revisión se basa en el catálogo de la exposición y en el debate público que generó, así como en el informe de la comisión revisora. La primera exposición fue concebida por Hannes Heer y se tituló "Guerra de exterminio. Crímenes de la Wehrmacht 1941 a 1944”. Se inauguró el año 1995, a 50 años del fin de la Segunda Guerra Mundial, y resumió y sistematizó los resultados de investigaciones académicas previas para presentarlas a un público más amplio. Sin embargo, provocó un intenso debate cargado de emociones tanto en la sociedad como en la prensa y la academia, generando una polarización de las posiciones. Tras críticas por lo que algunos consideraron un trabajo académico-museográfico poco riguroso, se cerró la exhibición y fue revisada por un comité de historiadores. Posteriormente, fue reinaugurada en el año 2002 con una nueva exposición liderada por Jan Philipp Reemtsma y llamada "Crímenes de la Wehrmacht. Dimensiones de la guerra de exterminio 1941-1944".

La primera exposición tenía como objetivo terminar con la leyenda del ejército 'limpio', instalada en la opinión pública desde 1945 y promovida por los altos generales. Según ellos, el ejército no había participado en el Holocausto y, por el contrario, solamente cumplió con sus deberes ${ }^{3}$. Este discurso limitaba el círculo de los perpetradores a un grupo pequeño de personas y pocas instituciones criminales como la Schutzstaffel (SS). Heer quería comprobar en la exposición que "el ejército llevó a cabo en los Balcanes y la Unión Soviética una guerra que apuntó a la eliminación de los judíos, los prisioneros de guerra y los civiles, teniendo millones de víctimas. (...) La institución formó parte activa e institucional de los crímenes." (Heer, 1996, p. 7) Además, quería impulsar un debate público al respecto (Heer, 1996, p. 7) ampliando el concepto de perpetrador en el imaginario público al incluir nuevos grupos de personas y organizaciones. Para eso indagó en los crímenes de guerra de la Wehrmacht en el Este, los que fueron presentados en una museografía tradicional de afiches con textos y fotos. Además, hubo un extenso espacio en forma de cruz de hierro (símbolo de la Wehrmacht) con fotografías sobre estos crímenes.

En el debate público destacaron actores como la prensa, políticos de diferentes niveles, académicos, grupos neonazis, grupos de izquierda y aso-

\footnotetext{
${ }^{3}$ Este mito fue difundido en un memorándum de varios generales nazi en los juicios de Núremberg de 1945 y en las memorias de los generales Dönitz y von Manstein, entre otros.
} 
ciaciones de ex-soldados de la Wehrmacht. Se mezclaron polémicas y críticas profesionales y se tornó altamente polarizado y emocional; complejo de manejar para sus creadores.

Este impacto tiene que ver con la gran cantidad de imágenes exhibidas en la exposición (1400 fotografías) y su presentación como testimonios e ilustración de los crímenes, mostrando y personalizando (aunque sin nombre) a los perpetradores de los crímenes de guerra en el lugar y acto del crimen, a sus víctimas y las consecuencias visibles. Sin embargo, la comisión revisora de historiadores criticó el uso ilustrativo (no analítico) y la poca rigurosidad museográfica y académica en la presentación de las imágenes (Bartov, Brink, Hirschfeld, Kahlenberg, Messerschmidt, Rürup, Streit, Thamer, 2000, p. 39) $)^{4}$ lo que muestra que la exposición no contaba con criterios definidos y coherentes para la presentación de fotografías de perpetradores, crímenes y víctimas.

Asimismo, según la comisión revisora, el gran impacto se debió a la presentación en un momento de desarticulación natural del grupo de memoria $^{5}$ de los soldados que habían vivido la guerra, dada la alta edad y muerte de sus miembros:

Este fenómeno general de desarticulación cobró aún más fuerza en el caso de la memoria de la Wehrmacht, dado que para la mayoría de los contemporáneos se empezó a de-construir masivamente una imagen histórica que se había logrado mantener a pesar de los conocimientos académicos. En cambio, entre muchos de los miembros de las generaciones medias y jóvenes la reevaluación se encontró con una creciente disposición de aceptar estas nuevas interpretaciones, si no las compartían ya desde antes. (Bartov et al. 2000, pp. 16-17)

En esta situación, los ex soldados, que fueron casi todos los hombres de las generaciones de preguerra y guerra ${ }^{6}$ se vieron enfrentados a la presión y angustia de tener que justificar su actuar durante la guerra. Este conflicto generacional se entrelazó con una polarización y politización del conflicto.

\footnotetext{
${ }^{4}$ Por ejemplo, se usaron presentaciones en secuencias para presentar los acontecimientos de un crimen, pero fotos de la misma serie se usaron para ilustrar ejemplos de otros crímenes.

${ }^{5}$ Los grupos de memoria en el sentido de Pierre Nora (2008) son grupos que comparten una memoria, dado que vivieron experiencias en un tiempo y contexto parecido.

${ }^{6}$ Esta generación se conforma por las personas nacidas antes de la Segunda Guerra Mundial que la vivieron como adolescentes y adultos. La gran mayoría de los hombres de esta generación tuvieron que participar en la guerra como soldados o policías.
} 
Finalmente, la comisión revisora criticó la forma de presentación de los contenidos por su falta de rigurosidad ${ }^{7}$ y por una tendencia a generar efectos emocionales con la selección y presentación de imágenes: "La exposición incluye (1) errores de contenidos, (2) imprecisiones en el uso del material y (3) generalizaciones y declaraciones sugestivas, sobre todo por el tipo de presentación" (Bartov et al., 2000, p. 91). La crítica demostró así, la falta de criterios museográficos y académicos, lo que se reflejó en un uso emocional e ilustrativo de las fotos y el uso de generalizaciones provocadoras en los títulos y textos ${ }^{8}$. En síntesis, la exposición, sin querer, reveló las faltas existentes en el mundo académico alemán referidas al uso de fotografías en archivos, investigación y exposiciones'. Si bien la comisión revisora reafirmó explícitamente los contenidos claves y el mensaje principal sobre el rol de la Wehrmacht en los crímenes de lesa humanidad expuestos en la primera exposición; y valoró el impulso para una vasta producción académica sobre el tema y de un debate público que ampliara los conocimientos académicos hacia la sociedad, sugirió realizar una nueva exposición en vez de corregir la primera (Bartov et al., 2000, pp. 91-92).

La nueva exposición fue exhibida entre 2002 y 2004 en diferentes ciudades de Alemania. Esta exposición reafirmó la declaración principal sobre el rol de la Wehrmacht en el Holocausto y la guerra de exterminio, causando reacciones públicas más moderadas. Sus creadores se hicieron cargo de las críticas de la comisión de historiadores, a través de una nueva presentación museográfica, nuevas investigaciones, estructura y contenidos, y además, preocupándose de enfrentar los intentos públicos de legitimar el actuar de los soldados en la Guerra. Estas legitimaciones declararon necesario revisar el contexto moral, institucional y judicial del momento histórico de los crímenes, ya que de acuerdo con esta postura los soldados actuaron hipotéticamente en un contexto en que operaban criterios morales y éticos diferentes a los actuales (Reemtsma, 2002, p. 5). O sea, la pregunta por el contexto valórico buscaba legitimar el actuar de los soldados y traspasar la responsabilidad por los crímenes, a través del argumento de la obediencia debida a los superiores.

\footnotetext{
${ }^{7}$ Ya que varias de las fotografías tenían cédulas erróneas, algunas ni siquiera mostraron soldados alemanes o crímenes de la Wehrmacht, sino de otros ejércitos, y otras fueron vinculadas erróneamente a casos que no correspondían.

${ }^{8}$ Por ejemplo "Guerra contra partisanos sin partisanos".

${ }^{9}$ Especialmente resaltó la falta de información secundaria en los archivos, referida a la procedencia, autor y origen de las fotos; en la investigación se demostró una falta de análisis crítico de fotografías, y en las publicaciones y exposiciones su uso ilustrativo en vez de analítico.
} 
Haciéndose cargo de revisar y contraargumentar este punto, la nueva exposición presentaba dos mensajes principales: (1) Demostró que los crímenes de guerra en el Este violaron los acuerdos internacionales, los valores éticos y las costumbres contemporáneas de guerra. Así, inclusive según estándares contemporáneos, eran ilegales. Además, indicó que estos crímenes fueron proyectados ya en la etapa de planificación de la guerra y no surgieron solamente de una escalada de violencia en terreno (Reemtsma, 2002, pp. 5-6). (2) Sin embargo, demostró también que cada acto criminal fue determinado además por los aspectos específicos de la situación, del contexto y de las actitudes personales. En cuanto a esto, Reemtsma (2002, pp. 22-23) profundiza especialmente en la responsabilidad individual de los victimarios ${ }^{10}$.

A partir de este argumento, Reemtsma (2002, pp. 21-23) elabora el concepto del Handlungsspielraum que refiere a la libertad de decidir sobre sus propios actos, es decir, que en nuestro actuar constantemente tomamos decisiones por una opción u otra. Siendo obvia la opción éticamente correcta, Reemtsma (2002) pregunta: “¿bajo qué circunstancias y condiciones qué comportamiento humano se puede y/o debe esperar de todos y cuál puede y/o debe considerarse como moralmente reprochable?" (p. 7). Consecuentemente, la última sala de la exposición confronta al visitante con distintas personas que optaron por diferentes caminos en situaciones parecidas. De esta manera involucra e invita a los visitantes -independientemente de su edad y relación con este periodo histórico- a reconocer diferentes opciones de actuar, no desde una postura moral superior, sino como punto de partida para un debate acerca de la sociedad en la que vivimos y la que queremos construir. Así el Handlungsspielraum resulta ser un concepto clave para el vínculo pasado-presente en el trabajo educativo sobre los perpetradores (Gryglewski, 2017, pp. 22-24).

\section{CRITERIOS MUSEOGRÁFICOS CONCRETOS}

Tras la experiencia de la Wehrmachtsausstellung, la reformulación de la exposición permanente de la Wewelsburg fue otro hito importante en la representación museográfica de los perpetradores de los crímenes del na-

\footnotetext{
${ }^{10}$ En cuanto a esto, el estudio de Christopher Browning (2011) sobre el Batallón de reserva 101 de la policía uniformada, que asesinó a miles de personas, en su mayoría judíos, demuestra claramente que al menos los policías tenían ciertos márgenes de interpretación de la mayoría de sus órdenes y podían evitar personalmente la participación directa en las ejecuciones de civiles.
} 
zismo. Esta exposición fue inaugurada en 2010, tras diez años de reflexión interdisciplinaria, planificación conceptual e intercambio con expertos y la academia. Gracias a ello, los expositores lograron definir cinco criterios museográficos concretos para la representación de perpetradores del nazismo, sus documentos, objetos y arquitectura.

La Wewelsburg es un sitio de memoria de la categoría Täterorte ${ }^{11}$. Estos lugares no están vinculados necesariamente a víctimas en el lugar, sino a miles de víctimas en otros lados, ya que fueron sitios desde donde se organizaron, prepararon y administraron los crímenes, o bien, fueron lugares simbólicos y representativos de organizaciones perpetradoras como la SS y otros. La Wewelsburg es un castillo del Renacimiento, que fue usado y proyectado durante el nazismo como centro ideológico y representativo para la élite de la SS. Esta construyó dos salas nuevas en el castillo que aún están intactas. El uso y las construcciones originales de la SS han causado una fascinación de grupos de neonazis por el edificio. Ya desde los años cincuenta el castillo aparece en literatura del género Fantasy, homenajeando a la SS y explicando la política del Tercer Reich con teorías conspirativas. Por ejemplo, el sol negro que adorna el suelo de una de las salas del castillo se ha vuelto un referente simbólico para grupos de extrema derecha en todo el mundo, que usan vestimentas y accesorios decorados con él. De hecho, los profesionales del sitio de memoria se dieron cuenta de que existía un peregrinaje de neonazis al castillo (Brebeck y John-Stucke, 2011).

Ante estos desafíos específicos y la experiencia de exposiciones anteriores sobre perpetradores de los crímenes nazi, se resolvió cambiar la museografía. La nueva exposición para el sitio tuvo que responder a la necesidad de generar un concepto claro para la representación de la SS (el grupo de perpetradores públicamente más conocido), que respondiera al mal uso del lugar por neonazis, para así evitarlo. Finalmente, el nuevo enfoque tuvo como objetivo responder a la situación de que en el archivo de la Wewels$\operatorname{burg}$ (y en general) existe una gran cantidad de fuentes históricas generadas por la propia SS, pero muy pocas fuentes generadas por las víctimas. Para enfrentar todos estos desafíos, el equipo museográfico plantea cinco criterios que buscan interferir en la transmisión de los mensajes ideológicos de los objetos afirmativos ${ }^{12}$, creados por los perpetradores, que podrían generar admiración o morbo, y en cambio enfatizar los objetos de las víctimas (John-Stucke, 2011, pp. 23-25):

\footnotetext{
${ }^{11}$ Una categoría de sitios de memoria en Alemania que se dedican a la investigación de los perpetradores y sus crímenes vinculados al sitio.

${ }^{12}$ Objetos y documentos generados por los nazi que por lo mismo tienden a afirmar su ideología.
} 
- Estética tipo depósito: Este principio propone que la estética y el diseño elegido para la exposición se orienten en el estilo de muebles de depósito, y busquen quitarle a la presentación cualquier aura mística o enigmática. Además, permite mirar los objetos desde diferentes perspectivas y ángulos.

- Tapar sin esconder: Con el objetivo de evitar cualquier posibilidad de homenaje a los objetos afirmativos, pero al mismo tiempo no "esconderlos" se implementan obstáculos museográficos para la observación. Por ejemplo, la observación de los emblemas nazi se interrumpe con una pegatina en los vidrios de la vitrina que también llevan los textos de cédulas pegados, no permitiendo una mirada (o toma de foto) sin obstáculos. También el posicionamiento del objeto influye en la visibilidad, si por ejemplo un retrato de un alto mando de la SS no se puede apreciar de frente, sino solamente de lado.

- Masividad: En vez de singularizar los objetos en una vitrina, agregándole valor museográfico, estos se presentan de manera masiva, dando la idea de que se trata de producciones al por mayor de material propagandístico.

- Contrastes: Con el fin de demostrar el contraste entre la ideología y la realidad, se complementan los ideales ideológicos de la SS transmitidos por los objetos, con información sobre el (in)cumplimiento de los SS de sus propios ideales.

- Contextualización responsable: A fin de interrumpir la transmisión ideológica de los objetos, estos se contextualizan con información que da a conocer el significado y las implicaciones violentas y criminales detrás de su contexto de producción o uso.

Para dar algunos ejemplos: Una figura decorativa que representa a una mujer como madre transmite el ideal nazi de la maternidad para dar luz a hijos y futuros soldados que sobrevivan la guerra y pueblen la "nueva Alemania". En la exposición, esta figura se contrasta con estadísticas que muestran que las familias de la SS tenían una tasa de natalidad por debajo del promedio de las familias en general (John-Stucke, 2011, p. 24). Por otro lado, un candelero Julleuchter que fue utilizado en la fiesta que reemplazaba la Navidad en la ideología nazi, a primera vista podría ser percibido como un objeto supuestamente inocente. Pero, según el criterio de la contextualización responsable, este se complementa en la exposición con fotos y documentos de su contexto de producción mediante trabajo forzado de presos del campo de concentración Neuengamme (John-Stucke, 2011, p. 25). 
Estos mismos conceptos museográficos se aplicaron para evitar el mal uso de los espacios arquitectónicos. Así, la "Sala sepulcro" (Gruft), que supuestamente iba a estar dedicada a velorios de altos rangos de la SS, se contextualiza con un ciclo de cuadros expresionistas del artista Josef Glahé sobre las consecuencias de los crímenes de la SS (Brebeck y John-Stucke, 2011, p. 16) ${ }^{13}$.

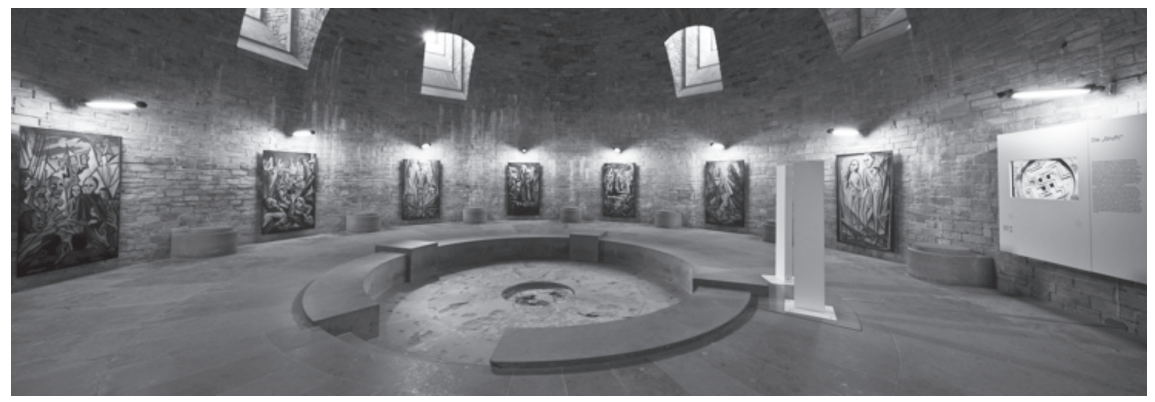

Figura 1. Wewelsburg (s.f.): Sala sepulcro [Fotografía]. Archivo Wewelsburg.

Por su parte, para interrumpir el impacto dominante del ornamento del sol negro en la "Sala de alto mando" (Obergruppenführersaal ${ }^{14}$ ), se usa el criterio de tapar sin esconder. Varios puf de pera y mesas de centro con folletos informativos tapan parcialmente el ornamento e invitan a sentarse de manera informal. Así interrumpen la estética dominante del símbolo en el suelo y se evita el impulso del público a detenerse respetuosamente alrededor del ornamento (Brebeck y John-Stucke, 2011, p. 17).

\footnotetext{
${ }^{13}$ Josef Glahé creó el ciclo para este mismo espacio en 1950.

${ }^{14}$ Obergruppenführer era un alto rango en la SS. La sala probablemente estuvo pensada para sus reuniones.
} 


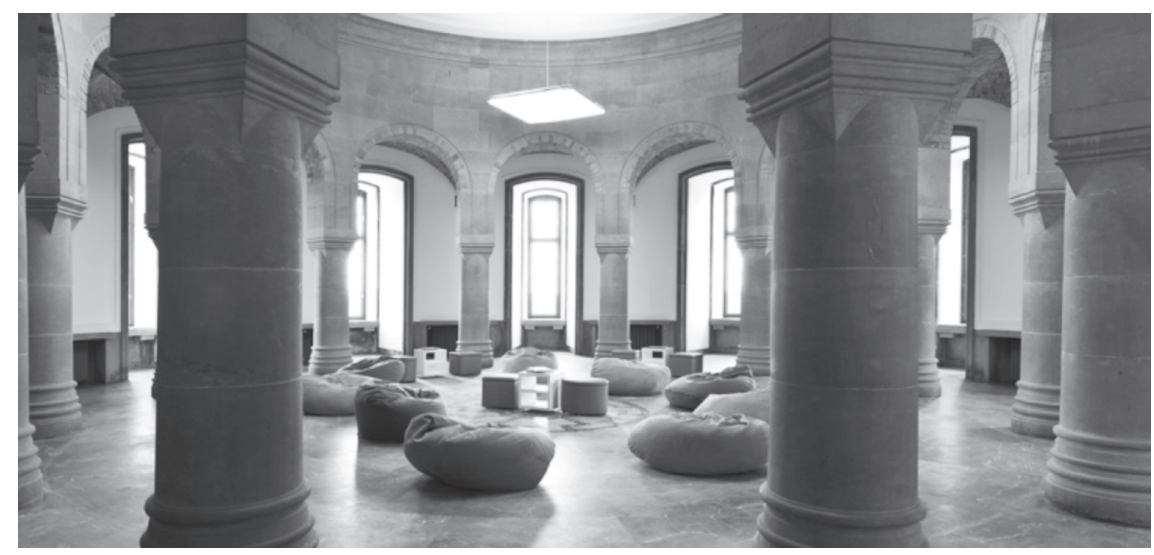

Figura 2. Wewelsburg (s.f.): Sala de alto mando [Fotografía]. Archivo Wewelsburg.

Anexo al castillo, en tiempos del nazismo, existía un campo de concentración con presos que tuvieron que realizar la construcción arquitectónica bajo trabajo forzado. Por lo mismo, existen algunas pocas fuentes de las víctimas en el archivo de la Wewelsburg. Para la presentación de estos documentos, objetos y testimonios, los expositores buscaron marcar la diferencia ética y estética a través de la aplicación de criterios museográficos distintos. Así, para los objetos del campo de concentración se aplicaron los criterios anteriormente nombrados, pero al revés. Esto quiere decir que estos objetos se encuentran singularizados en vitrinas que los protegen y destacan, y nada interfiere con su apreciación estética. Las cédulas y los textos se encuentran en el marco de la vitrina y no obstruyen su visión, además, se disponen focos de luz para resaltarlos y paspartú para los documentos; adicionalmente, se exhiben testimonios de sobrevivientes que contextualizan la historia de cada objeto (John-Stucke, 2011, p. 25).

Asimismo, en vez de cerrar las salas históricas al público y "esconder" los objetos y documentos de la SS en el depósito, el equipo de la Wewelsburg ha optado por exponerlos para tematizar su transmisión ideológica. A través de la presentación museográfica el sitio toma claramente posición: obstaculiza los objetos y símbolos de los perpetradores para evitar un mal uso, quitándole de manera museográfica el poder estético intencionado originalmente, y cambiando y reinterpretando los usos de los espacios arquitectónicos. En cambio, los objetos de las víctimas cuentan con el espacio para ser apreciados sin obstáculos y para desarrollar su estética y aura de objeto histórico original. El equipo presenta abiertamente su estrategia y 
criterios museográficos en el catálogo del sitio, entre otros lugares, transparentando sus objetivos.

\section{DISCUSIÓN}

A partir de los casos revisados derivan reflexiones éticas respecto a la representación museográfica de perpetradores. Estas nos conducen a la pregunta por el objetivo de una exposición. Hemos visto en el caso de la Wehrmachtsausstellung I que un tema controvertido puede impulsar debates emocionales y a la larga avances tanto en la opinión pública como en las disciplinas académicas y museográficas implicadas.

Especialmente, en el caso de dilemas éticos, como lo es la representación de perpetradores de crímenes de lesa humanidad o violaciones de los DD.HH., a los expositores se plantea la pregunta si se puede y/o debe tomar posición ética. A partir de la experiencia alemana es un deber tomar esta posición clara a favor de los DD.HH., pero entonces, ¿qué medios museográficos son legítimos de usar para transmitir el mensaje? O sea, ¿cuáles son los límites para no caer en la manipulación? Y ¿qué impulsos queremos generar en las audiencias? La Wehrmachtsausstellung II apuesta por un relato y una museografía de estilo más académico combinado con preguntas inquietantes que confrontan al público con la pregunta ética por la responsabilidad individual o el Handlungsspielraum. En esta misma línea, el equipo de la Wewelsburg adopta posiciones y criterios claros y transparentes para distinguir la representación de perpetradores y víctimas en su exposición, así como para generar conciencia respecto al mensaje ideológico que siguen transmitiendo sus objetos y documentos.

Así, estas exposiciones adoptan posiciones éticas claras contra los crímenes expuestos, pero se diferencian por sus criterios museográficos y los contextos sociales y políticos en los que se generaron. Su objetivo de difundir los conocimientos académicos entre un público amplio no especializado se ve favorecido o desafiado no solamente por diferentes museografías, sino también por diferentes contextos sociales y políticos que generan públicos distintos. La Wehrmachtsausstellung I se presentó al público en el momento de un cambio generacional en la sociedad, generando debates emocionales y la materialización de un conflicto generacional sobre memoria e identidad colectiva. En cambio, el público de la Wewelsburg corresponde mayoritariamente a generaciones que no vivieron el tiempo histórico al que se refiere la exposición. Esta distancia desafía a las nuevas exposiciones a hacer partícipe a estas nuevas audiencias. 
El trabajo con estas presenta ventajas y desafíos diferentes. Los debates que se generan acerca del pasado son menos emocionales, ya que no cuestionan directamente identidades personales y colectivas. Por lo mismo, existe más disponibilidad para integrar los conocimientos académicos en la opinión pública, aunque cuestionen el actuar de los propios antepasados. Sin embargo, cuesta más motivar e involucrar a estos públicos nuevos en la temática. Para lograr esto, es necesario generar vínculos motivadores entre el pasado y presente. La Wehrmachtsausstellung II desafía al visitante a través del concepto Handlungsspielraum a debatir sobre la sociedad que queremos construir, involucrándola desde su posición ética, más allá de su edad o cualidad de testigo de la época. De este modo, la integración de preguntas inquietantes resulta ser interesante para generar un vínculo positivo y motivador con la temática.

\section{CONCLUSIONES PARA EL DEBATE CHILENO}

A lo largo de este artículo se ha revisado la representación de perpetradores de crímenes nazi en exposiciones museográficas en Alemania, con el objetivo de identificar criterios expositivos y entregar elementos para el debate sobre la representación de perpetradores de crímenes de lesa humanidad y violaciones de DD.HH. en diferentes contextos.

La revisión de las exposiciones alemanas resalta (1) la importancia de criterios museográficos para la representación de perpetradores de crímenes de lesa humanidad, (2) la necesidad de considerar el contexto social de la exposición para generar maneras de involucrar las audiencias más allá de replicar la polarización de la sociedad y (3) la integración de nuevos hallazgos académicos.

Para el debate chileno sobre la representación de violadores de los DD.HH. lo anterior promete ser un interesante punto de partida, en lo siguiente:

1. El debate chileno requiere la elaboración de criterios museográficos para la representación de perpetradores de violaciones de los DD.HH, para así distinguirlos de la representación museográfica de otros actores (especialmente de las víctimas). En el caso chileno se observan, parecido a la experiencia de la Wewelsburg, mensajes ideológicos y deshumanizantes inherentes a los documentos y objetos afirmativos de los perpetradores, donde sigue operando la lógica legitimadora de la doctrina de seguridad nacional, 
la criminalización de las víctimas, el desprecio a la política, y los valores nacionalistas y militarizados ${ }^{15}$. Por ende, las exposiciones museográficas deberían encontrar criterios para transparentar y deconstruir estos mensajes a fin de generar conciencia y aprendizajes.

2. El debate por la exposición "Hijos de la Libertad" es una expresión de los procesos sociales a casi 30 años del fin de la dictadura. Aunque existe un relato oficial acerca de la dictadura en los informes de verdad del Estado, en el espacio público siguen operando interpretaciones polarizadas, protagonizadas por las primeras y segundas generaciones que vivieron la dictadura, pero también por los nietos nacidos post-dictadura (Höhl, 2010), es decir, el debate sigue amenazando identidades individuales y colectivas.

En el debate polarizado acerca de la Wehrmachtausstellung I en los años 1990 en Alemania resultó positivo introducir el concepto del Handlungsspielraum a través de preguntas inquietantes, más que provocadoras. Aunque el debate chileno se desarrolla en otro contexto histórico y social, buscar preguntas inquietantes que intenten romper con la polarización e involucren a las nuevas generaciones, parece ser un ejercicio necesario.

3. Los puntos anteriores pueden nutrirse de la escasa, pero interesante investigación sobre perpetradores de violaciones de los DD.HH. en el caso chileno. Entre las reflexiones que pueden ser adaptadas para desarrollar criterios museográficos y preguntas inquietantes resalta especialmente el intento de romper con la limitación del debate público a la figura de Pinochet (y su policía secreta), representado como el mal personalizado. Esto busca no perder de vista los casos incómodos de complicidad, delación y simpatía más cotidianos, pero en suma igual de importante para sostener el sistema autoritario y represivo (Estefane y Thielemann, 2020; Lazzara, 2018). Además obliga a asumir el peligro de que personas "normales" puedan volverse perpetradores en ciertas circunstancias (Browning, 2011). También, resalta la revisión de casos ambiguos entre los conceptos de víctima y victimario (Passmore, 2017) y la pregunta por las reacciones de los "sujetos implicados" en las familias de los victimarios (Lazzara, 2020). Así que, es imprescindible guiar la mirada a las complejidades, ambigüedades y grises entre las categorías de perpetrador de violaciones de los DD.HH., sociedad civil e inclusive víctima.

\footnotetext{
${ }^{15}$ Por ejemplo, "Exterminados como ratones" (La Segunda, 1975), "No podrán salir del país: ExLíderes del PC, MIR y MAPU son delincuentes" (La Estrella de Iquique, 1973) o el "Discurso por el primer aniversario del pronunciamiento militar" (11 de septiembre 1974).
} 
4. Finalmente sugiero reflexionar acerca del lugar y tipo de exposición a elegir para la representación de perpetradores. La exposición "Hijos de la Libertad" no fue una exposición exclusiva sobre perpetradores, sino que la cita y foto de Pinochet solamente fueron incluidos marginalmente en una exposición sobre el concepto de libertad en los 200 años de la Independencia de Chile. A raíz de la discusión presentada en este artículo, en este marco no habría sido posible elaborar la investigación y reflexión profunda necesarias para generar criterios elaborados para la representación de violadores de DD.HH. En cambio, los sitios de memoria, como señalan Rebolledo y Sagredo (2020), suman una dimensión ética adicional referida al concepto de recuperación del lugar por las víctimas que busca resignificarlo. ¿Qué rol puede jugar la representación de los victimarios en estos lugares? Va a ser interesante seguir el proceso de reflexión que está llevando a cabo el equipo del Parque por la Paz Villa Grimaldi al respecto.

\section{REFERENCIAS}

Arendt, H. (1999). Eichmann en Jerusalén, un estudio sobre la banalidad del mal (Trad. de Carlos Ribalta). Barcelona: Lumen.

Bajohr, F. (18 de junio de 2013). Neuere Täterforschung. [Artículo en Docupedia]. Recuperado de: http://docupedia.de/zg/bajohr_neuere_taeterforschung_v1_de_2013

Bartov, O., Brink, C., Hirschfeld, G., Kahlenberg, F., Messerschmidt, M., Rürup, R., Streit, Ch. \& Thamer, H.-U. (2000). Bericht der Kommission zur Überprüfung der Ausstellung "Vernichtungskrieg. Verbrechen der Wehrmacht 1941 bis 1944". [Informe de la comisión revisora]. Recuperado de: www. verbrechen-der-wehrmacht.de/pdf/bericht_kommission.pdf

Basaure, M. (30.11.2018). La monstruosidad y Pinochet. El Desconcierto. Recuperado de: www.eldesconcierto.cl/2018/05/24/la-monstruosidad-y-pinochet/

Brebeck, W. E. \& John-Stucke, K. (2011). Wewelsburg - Zum historischen Ort. En W. Brebeck, F. Huismann, K. John-Stucke y J. Piron (eds.). Endzeitkämpfer, Ideologie und Terror der SS (pp. 10-19). Berlin: Deutscher Kunstverlag.

Browning, C. (2011). Aquellos hombres grises. El batallón 101 y la Solución Final en Polonia (Trad. de M. Batista). Barcelona: Edhasa.

Estefane, A. y Thielemann, L. (2020). El mal, la libertad y Pinochet. Atenea, 521, 189-209.

Exterminados como ratones. (24 de julio de 1975). La Segunda, 1.

Greve, M. (2003). Täter oder Gehilfen? Zum strafrechtlichen Umgang mit NSGewaltverbrechen in der Bundesrepublik Deutschland. En U. Weckel \& E. Wolfrum (ed.). "Bestien" und "Befehlsempfänger". Frauen und Männer in 
NS-Prozessen nach 1945 (pp. 194-221). Göttingen: Vandenhoeck \& Ruprecht.

Gryglewski, E. (2017). ¿Por qué investigar sobre violadores de Derechos Humanos y autores de crímenes de lesa humanidad? En C. Aguilera y D. Jara (eds.). Pasados inquietos (pp. 16-33). Santiago: Museo de la Memoria/Foro Urbano.

Heer, H. (1996). Einleitung. En Hamburger Institut für Sozialforschung (ed.). Vernichtungskrieg. Verbrechen der Wehrmacht 1941 bis 1944. Ausstellungskatalog. Hamburg: Hamburger Edition.

Höhl, J. (2010). Die Polarisierung der chilenischen Gesellschaft vom Ende der Diktatur Pinochets 1988 bis heute. Arbeitspapiere zur Lateinamerikaforschung, II-10. Recuperado de: https://lateinamerika.phil-fak.uni-koeln.de/ sites/aspla/bilder/arbeitspapiere/hoehl.pdf

Jara, D. (2016). Representaciones públicas de perpetradores en la posdictadura chilena: el informe Rettig y el caso Letelier. [Paper presentado en el Seminario Pasados Inquietos] Museo de la Memoria, Santiago.

John-Stucke, K. (2011). Genese, konzeptionelle Grundsätze und Gliederung der Ausstellung "Ideologie und Terror der SS”. En W. Brebeck, F. Huismann, K. John-Stucke, \& J. Piron (eds.). Endzeitkämpfer, Ideologie und Terror der SS (pp. 20-31). Berlin: Deutscher Kunstverlag.

Lazzara, M. (2018). Civil Obedience. Complicity and Complacency in Chile since Pinochet. Wisconsin: University of Wisconsin Press.

Lazzara, M. (2020). Familiares de colaboradores y perpetradores en el cine documental chileno: memoria y sujeto implicado. Atenea, 521, 231-248.

Musial, B. (1999). Deutsche Zivilverwaltung und Judenverfolgung im Generalgouvernement. Eine Fallstudie zum Distrikt Lublin 1939-1944. Wiesbaden: Harrassowitz Verlag.

No podrán salir del país: Ex-Líderes del PC, MIR y MAPU son delincuentes. (9 de octubre de 1973). La Estrella de Iquique, 1.

Nora, P. (2008). Pierre Nora en Les lieux de mémoire (Trad. de Laura Masello). Montevideo: Ediciones Trilce.

Passmore, L. (2017). The wars inside Chile's barracks: Remembering military service under Pinochet. Wisconsin: University of Wisconsin Press.

Rebolledo, J. (2012). La danza de los cuervos: El destino final de los detenidos desaparecidos. Santiago: Ceibo ediciones.

Rebolledo, D. y Sagredo, O. (2020). ¿Cómo representar a los represores en un sitio de memoria? El caso del Parque por la Paz Villa Grimaldi. Atenea, 521, 211-229.

Reemtsma, J. P. (2002). Über den Begriff "Handlungsspielraum". Mittelweg 36, 11(6), 5-24.

Welzer, H. (2005). Täter: Wie aus ganz normalen Menschen Massenmörder werden. Frankfurt: Fischer Taschenbuch Verlag.

Wildt, M. (2003). Generation des Unbedingten. Die Führungskorps des Reichssicherheitshauptamtes. Hamburg: Hamburger Editionen. 